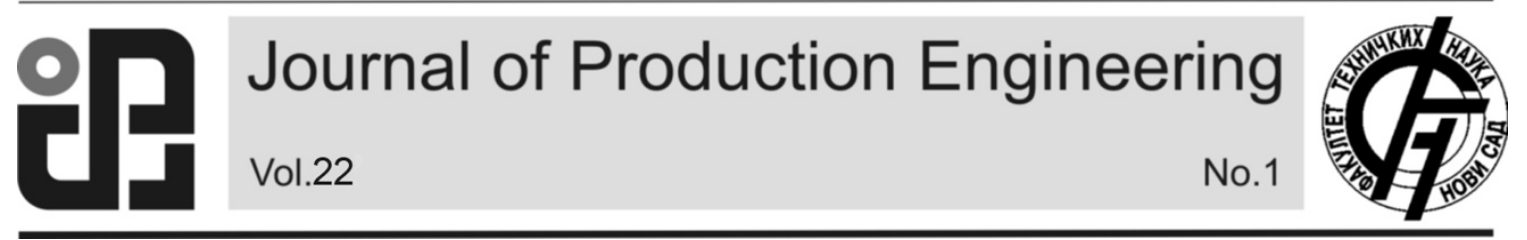

JPE (2019) Vol.22 (1)

Đurić, I., Ilić, V., Ralević, N.

Original Scientific Paper

\title{
SHAPE DESCRIPTORS APPLIED TO THE ANALYSIS OF DIFFERENT TYPES OF THE ENGINEERING ELEMENTS
}

Received: 09 January 2019 / Accepted: 29 April 2019

\begin{abstract}
The aim of this research is to analyse, numerically describe and classify the elements from the image, using the shape descriptors. The paper discusses standard shape descriptors based on discrete moments associated with the certain element shape, as well as their combinations with other global shape descriptors. The new shapebased object analysis approach is illustrated by studying two essentially diverse types of the engineering elements, different by their nature and origin, but similar according to the visual representation of their shape characteristics. The usefulness and efficiency of the considered descriptors in such classification tasks is illustrated by experimental results.
\end{abstract}

Key words: shape descriptors, measures, engineering elements

Deskriptori oblika primenjeni na analizu različitih vrsta inženjerskih elemenata. Cilj rada predstavlja analizu $i$ numerički opis elemenata sa slike, korišćenjem deskriptora oblika. U radu su razmatrani standardni deskriptori zasnovani na diskretnim momentima pridruženim obliku, kao i njihovim kombinacijama sa drugim globalnim deskriptorima oblika. Korisnost $i$ efikasnost razmatranih deskriptora u zadacima numeričke karakterizacije $i$ klasifikacije različitih inženjerskih elemenata ilustrovana je odgovarajućim eksperimentalnim rezultatima.

Ključne reči: deskriptori oblika, momenti, inženjerski elementi

\section{INTRODUCTION}

This research presents one interdisciplinary approach which uses image processing tools based on the shape analysis, combined with various machine learning algorithms in the tasks of analyzing, recognizing and classifying the different types of engineering elements. In order to test the proposed methodology, we used digital images of two essentially different types of engineering elements such as columns of the five Classical orders of architecture, as well as the machine elements obtained as the output products of the corresponding manufacturing cycle. Given that the digital representations of such types of the engineering elements have similar shape characteristics, in this paper, we will present a relatively new concept of analysing, comparing, or classifying the elements observed. The research is based on the two main steps: 1) analysis of the certain, suitable for numerical characterization, features of the shapes of the elements we are considering; and 2) designing the appropriate methods (i.e., measures) for the numerical evaluation of the considered shape features. Numerical characteristics, defined in such a way, are then used as the coordinates of feature vector of the observed element. Such a correspondence between the 'space' of the elements and associated feature vector space allows us to perform the certain object analysis tasks in the feature vector space rather than in the initial space of the observed elements. The concept presented in the paper is based on the consideration of only a few fairly simple shape descriptors and associated shape measures, relying on the use of discrete moments assigned to the shape considered.

\section{SHAPE DESCRIPTORS}

Shape is one of the basic attributes of the object (along with texture and color), and as such it does not require a formal definition. The shape can usually be presented as a bounded, not necessarily connected, planar set, while in the black-white digital images can be represented as a set of the black pixels represented on a white background.

In this research, we use several measures that are defined using the appropriate moments related to the shape observed. Geometric moment of order $p+q$ of a given shape $S$ is a quantity $m_{p, q}(S)$ defined as

$$
m_{p, q}(S)=\iint_{S} x^{p} y^{q} d x d y
$$

Some of the elementary properties of the shape, such as size (i.e., area) and position (i.e., centroid) of the shape, can be effectively expressed using the appropriate moments of order not greater than 1. For example, the zero-order moment, $m_{0,0}(S)$, represents the shape area, while the coordinates of the centroid are given as

$$
\left(x_{c}, y_{c}\right)=\left(\frac{m_{2,0}(S)}{m_{0,0}(S)}, \frac{m_{0,2}(S)}{m_{0,0}(S)}\right)
$$

In order to illustrate the measures applied in the research, we used normalized moments $\mu_{p, q}(S)$, defined as 


$$
\begin{aligned}
& \mu_{p, q}(S)=\frac{1}{m_{0,0}(S)^{\frac{p+q+2}{2}}} . \\
& \cdot \iint_{S}\left(x-x_{c}\right)^{p}\left(y-y_{c}\right)^{q} d x d y
\end{aligned}
$$

Given that elements we are considering can be described both as the single-component shapes (the whole shape is treated as a single component), and as the object with naturally defined components (the shape is considered to be a multi-component one), for our research, of particular importance, are measures originally designed both for the single-component, but also for the multi-component shapes. Following this observations, the shape measures for which we are interested in are the first $\mathrm{Hu}$ moment invariant $H_{1}(S)$, defined in [1] as

$$
H_{1}(S)=\mu_{2,0}(S)+\mu_{0,2}(S),
$$

and moment invariant $D(S)$, defined for multicomponent shapes in [2] as

$$
D(S)=H_{1}(S)-\frac{1}{m_{0,0}(S)^{3}} \sum_{i=1}^{n} m_{0,0}\left(S_{i}\right)^{3} H_{1}\left(S_{i}\right) .(5)
$$

\section{MOTIVATION}

In this paper, we want to illustrate a new shapebased object analysis approach to studying two diverse types of the engineering elements, different by their nature and origin, but similar according to the visual representation of their shape characteristics. In accordance with this, the certain shape descriptors, and the corresponding shape measures associated with them are analyzed. In order to test the usefulness and efficiency of the descriptors considered in the object analysis tasks, we have performed the experiments on the elements such as columns of the five Classical orders of architecture and machine elements representing the output of the certain production process.

\subsection{The Classical orders of architecture}

The major elements of the Classical orders of architecture are the five types of the column, known as Tuscan, Doric, Ionic, Corinthian, and Composite. The column can be divided into its basic parts: the base, the shaft, and the capital, which are further composed of a series of components. Each order is characterized by the proportion relationships of one component to another. The main method of proportioning each of the orders uses the diameter of the column above its base as a module $[3,4,5]$. The basic measure that characterizes each of the columns of the classical orders is the ratio of the diameter of the column above its base to the column height. Apart from the ratio of proportions, the columns differ by their capitals, each of which is specifically designed and decorated. The types of columns have been elaborated by numerous great theorists through the entire history of architecture, with variations in defining the basic module.

However, automatic identifying each of the five Classical orders of architecture by observation of its proportion and visual aesthetic details is usually common for the experts in the field, such as architects, artists, art historians, etc.

Nowadays, with the rapid development of the computer graphics, as well as image acquisition technologies, there is a great possibility to include various tools of machine learning, artificial intelligence, and computer vision in tasks of this kind. Since the columns of the five Classical orders can be described as a specific language of form, defined by the set of rules, it is possible to translate such a system into the machine language by associating the column shape attributes with a numerical characterization.

\subsection{Elements of the FMS (Flexible manufacturing systems)}

FMS (Flexible manufacturing systems) is a manufacturing technology which aims to achieve high level of flexibility and automation in the product development, in order to reduce product cost and delivery times [6,7]. The basic intention of the FMS is a production of one or more families of products and parts, with a development and an implementation of them, based on the application of the concept of group technology [7].

Starting from the principle of classification and product grouping, the total assortment of parts of the production system can be systematized according to the construction-technological similarity, or divided into certain entities for which the concept of group technology is rationally applied. On the basis of group technology established by Mitrofanov [8], and as a result of the research carried out in [9], a new approach to production was developed - a group approach in designing effective production structures. Using this approach, based on the classification of parts in the production process, groups of geometrically and technologically similar parts are created - operating groups (families), which form the basis for a group approach in the design of technological processes.

In [7], the authors present a methodology for the development and application of FMS (Flexible Production Systems) on the example of the formed technological group of rotary parts (Fig. 1.). The first phase within the proposed methodology implies the technological basics for the development and application of FMS, and consists of several tasks [7].

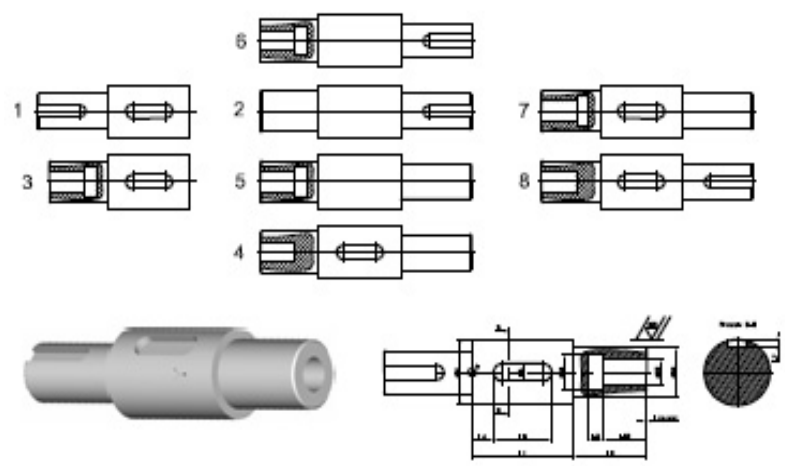

Fig. 1. An example of the one operating group (family) of a product parts [7] 
The focus of this paper is on the task of the analysis of the production program and the formation of technological/operational groups [6,7]. The main idea of this research is to test the application of the shape descriptors in the tasks of classification of the elements of the FMS and the creation of the operating groups (families). Based on the geometrical characteristics of the longitudinal sections of one single operating group (family) of the parts (Fig. 1.), we propose shape descriptors and the corresponding measures associated with them to numerically describe the product parts.

\section{EXPERIMENTAL RESULTS}

In order to test the approach presented, we have used the digital images of the technical drawings of both, elements of the five Classical orders of architecture, as well as the elements of the FMS, used as the parts of the machine production process.

\subsection{First experiment: The classification of the elements of the Classical orders of architecture}

For the classification of the columns, we used the technical drawings of the sections of the elements of the Classical order of architecture, as they are illustrated in [4]. In the book The Classical Orders of Architecture [4], the author presents, in a comparative way, the columns defined by the most important theoreticians, and finally created his own idealized form and proportions for each type of column. Figure 1 illustrates the columns of the Classical orders of architecture in their interrelation, whereas the main unit of proportion (the module) represents the diameter of the column above its base, while the scale bar on the figure determines how many times the module is contained in the column height. The idealized measure of the author (Fig. 2.) defines the proportions of the columns in the following way: the height of the Tuscan column contains seven diameters (Fig. 2. - Tuscan); Doric - eight (Fig. 2. - Doric); Ionic - nine (Fig. 2. Ionic); Corinthian (Fig. 2. - Corinthian) and Composite (Fig. 2. - Composite) ten diameters. The exact measure of the module varies among the authors analyzed in this paper. In this research we considered the orders defined by five authors: Serlio, Vignola, Paladdio, Gibbs and Chitham, described in detail in [4]. From the source images, only shapes of the columns were taken into account during the experiments. On the Fig. 2., the column shape, composed of the base, the shaft and the capital, is represented by the scale bar illustrated by numbers from 0 to $7,8,9$ or 10 , depending on the type of the column. The supporting element of the order stylobate (Fig. 2.: part of the order under the point 0 on the scale bar), was not taken into account, since, according to various illustrations, it does not necessarily have to be present and does not constitute an essential element of the order [4]. Also, the entablature, which rests on the column (Fig. 2.: the part marked on the scale bar with a number $7,8,9$ or 10 depending on the type of order) was not considered in the experiments, since, as a unique element of the classical order can be further broken down into a series of components that are in proportional relation, and whose additional analysis are out of the scope of the research presented in this paper.

In order to illustrate the applicability and usefulness of the analyzed shape descriptors in the tasks of the identifying and classifying the columns of the five orders of Classical architecture, a test set containing 25 digital images (five types of columns of five different authors) was used. Given that the standard architectural proportions are based on the measurements of certain characteristics of individual parts of the observed columns, certain pre-processing of the original images was required in order to prepare them for the application of the previously described measures.

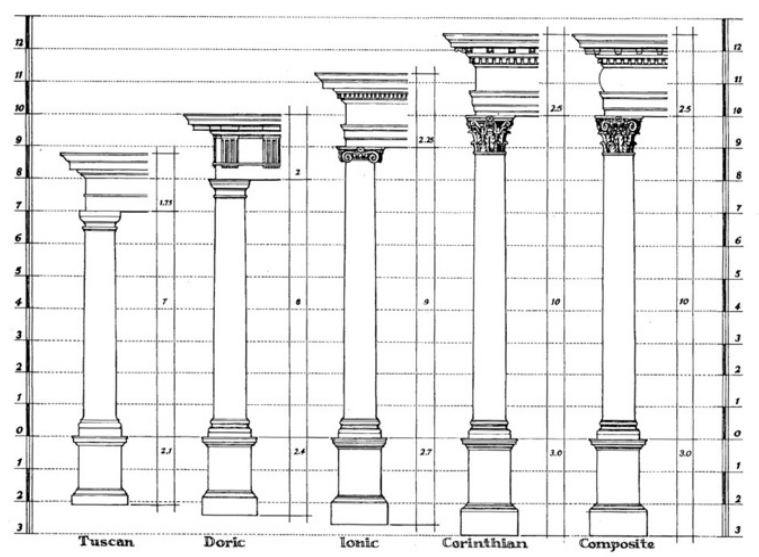

Fig. 2. Comparative interpretation of the five orders of Classical architecture by Robert Chitham [4]

The considered columns can be described as the whole shape (the whole column is treated as one component), but also as a complex object (the corresponding parts of the columns are the base, the shaft, and the capital). In addition to the measures described in (4) and (5), we designed two global column measures: $P_{l}(S)$ and $P_{2}(S)$. The proposed global measures, in a certain way, represent the corresponding expansion of the column proportions considered in defining the idealized measure in [4]. The given measures are defined as follows:

$$
\begin{aligned}
& \mathrm{P}_{1}(\mathrm{~S})=\frac{\text { column hight }}{\text { diameter of the column base }} \\
& \mathrm{P}_{2}(\mathrm{~S})=\frac{\text { column shaft hight }}{\text { diameter of the column shaft }}
\end{aligned}
$$

For the classification of the digital images of the observed test set, the 3-NN classifier, based on the Mahalanobis distance was used. The classification results obtained using the previously described shape measures, individually or by their respective combinations, are shown in Table 1 . The results of the classification were obtained using the leave-one-out machine learning strategy whereas, in all possible divisions of an initial test, a set of 25 digital images, 24 of them are used for training (i.e., designing) the classification model, while the examined model is then evaluated on the remaining image of the test set. 


\begin{tabular}{|l|c|}
\hline \multicolumn{1}{|c|}{ Shape measures } & Classification accuracy \\
\hline$P_{I}(S)$ & $40 \%$ \\
\hline$P_{2}(S)$ & $56 \%$ \\
\hline$D(S)$ & $60 \%$ \\
\hline$P_{I}(S)+D(S)$ & $64 \%$ \\
\hline$H_{I}(S)$ & $68 \%$ \\
\hline$P_{2}(S)+D(S)$ & $68 \%$ \\
\hline$P_{2}(S)+H_{I}(S)$ & $76 \%$ \\
\hline$P_{I}(S)+H_{I}(S)+D(S)$ & $80 \%$ \\
\hline$P_{2}(S)+H_{I}(S)+D(S)$ & $84 \%$ \\
\hline
\end{tabular}

Table 1. Classification results (second columns) obtained using the described shape measures, as well as by using their combinations (first column).

The achieved accuracy of the classification shows that the measures of the shape descriptors (given in (4) and (5)) individually, or combined with the corresponding global measures of certain column components (defined in (6) and (7)), can be very successfully applied to the proposed classification task. Also, the achieved classification results are in accordance with the theoretically proven properties that the observed moment invariant $H_{l}(S)(4)$, as well as $D(S)(10)$ satisfy. The latter follows from the fact that, according to the theoretical results presented in [10], the corresponding measure of the shape circle, based on the first Hu moment invariant $H_{I}(S)$ can also be used as an appropriate measure of the linearity of the observed shape. In other words, 'less circular' shapes can be understood as 'more linear', and vice versa. The experimental results completely coincide with this fact, proving that some columns are more linear, such as the Composite type in relation to Tuscan, which is also theoretically considered to be the most massive [3], or "the least linear" than the others orders of Classical architecture. On the other hand, on the basis of the theoretical results shown in [2], the considered moment invariant $D(S)$, as an appropriate measure of the disconnectedness of the components of a shape, in a certain way numerically evaluates mutual disconnection of the components of the column shape (i.e., the base, the shaft, and the capital). The obtained results are consistent with the expected results. Thus, for example, results that the components of the Ionic column have the lowest value of disconnectedness, while the components of the Tuscan column are highly disconnected. This phenomenon can be explained through the analysis of the column capitals. The Tuscan capital, although quite similar to Doric, contains a smaller number of tiny profiles than Doric [3], while the capital of Ionian column is distinguished by a very specific shape, a scroll-like ornament, so-called volute.

\subsection{Second experiment: The classification of the FMS elements of the machine production process}

For the classification of FMS elements of the machine production process, we used the technical drawings of longitudinal sections of one single operating group (family) of the product parts, as they are illustrated Figure 1. Digital images of the sections of the product parts were firstly converted into its binary representations (Fig.3a.), by using a threshold selection method from gray-level histograms [11]. In order to evaluate disconnectedness of the components of a shape, we first isolated the homogenous components from the binary images, in terms of its visual representation (Fig.3b.).
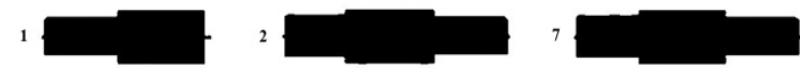

a)

b)
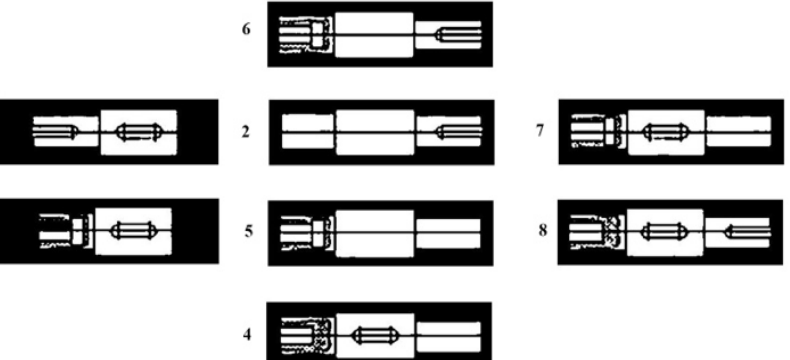

Fig. 3. a) binary (single-component); b) multicomponent representation of the product parts of the one FMS operating group (family)

Besides the first $\mathrm{Hu}$ moment invariant $H_{l}(S)$, and the measure of the disconnectedness of the components of a shape $D(S)$, for the classification FMS elements we have employed additional three shape descriptors such as:

1) Shape rectangularity, defined as the ratio of the areas of the shape and its minimal bounding rectangle:

$$
\operatorname{Rect}(\mathrm{S})=\frac{\operatorname{Area}(\mathrm{S})}{\text { Area }(\text { minimal_bounding_rectangle }(\mathrm{S}))}
$$

2) Moment-based shape elongation, obtained from the

method for computing the shape orientation, relying on the axis of the least second moment of inertia [12]:

$$
\operatorname{Elong}(S)=\frac{\mu_{2,0}(S)+\mu_{0,2}(S)+\sqrt{4 \mu_{1,1}(S)+\left(\mu_{2,2} 0(S)-\mu_{0,2}(S)\right)^{2}}}{\mu_{2,0}(S)+\mu_{0,2}(S)+\sqrt{4 \mu_{1,1}(S)+\left(\mu_{2,2} 0(S)-\mu_{0,2}(S)\right)^{2}}}
$$


3) The first affine moment invariant $A_{l}(S)[13]$ :

$$
A_{1}(S)=\frac{\mu_{2,0}(S) \mu_{0,2}(S)-4 \mu_{1,1}(S)^{2}}{m_{0,0}(S)^{4}}
$$

Table 2 shows the results obtained for the corresponding machine elements of the single operating group (i.e. family), using the previously described shape measures. The results achieved do not contradict our perception of how such descriptors should act, and they are also consistent with the theoretical observations related to these descriptors. For example, in the case of the first affine moment invariant $A_{l}(S)$ it could be noticed that the computed values (given in the last column in the Table 2) are approximately equal to $1 / 144$, which is the value of the first moment invariant for the rectangle. Such a property of $A_{1}(S)$ are in accordance with the theoretical considerations, given that the shapes presented in Fig. 3a. are of approximately rectangular shape, if they are considered as the single-component shapes. The same reasoning applies if the presented shapes are measured using the rectangularity $\operatorname{Rect}(S)$. It might be said that the shapes shown are of the same rectangularity, which also coincides with our perception of how much rectangular are the observed shapes.

However, if the shapes considered are viewed as the multi-component ones, it could be noticed that, according to computed $D(S)$ values, the most disconnected shapes are those enumerated with 4, 7 and 8 (Fig. 3b.). The computed values are also consistent with their theoretical considerations, and our expectations given that such shapes could be considered as the most disconnected ones, among the shapes presented. If the shapes presented are arranged according to measured $H_{l}(S)$ values, it could be noticed that the two least ranked shapes (shapes enumerated with 3 and 1 in Fig. 3b.) are the shapes which could be recognized as the least elongated ones. These results are also in accordance with the computed Elong $(S)$ values, given that the least elongated shapes, viewed as the multi-component ones, are the shapes enumerated with 3 and 1 (Fig. $3 b$.). Moreover, if the shapes presented are ranked in accordance with increasing $H_{l}(S)$ values, then the ranking $3,1,5,8,4,2,7,6$ is achieved. If the same reasoning is applied if the elongation measure Elong $(S)$ is applied, then slightly different ranking $3,1,5,8,4,6,2,7$ is obtained. It could be noticed that the differences among the rankings are in the case of the second, sixth and seventh shapes presented in Fig. 3b. Such a property of $H_{l}(S)$ and $\operatorname{Elong}(S)$ can be understood as a desirable in some shape-based object analysis tasks, given that in such cases these two shape measures could be combined and used together to improve performance of the different object analysis tools.

\begin{tabular}{|l|l|l|l|l|l|}
\hline $\begin{array}{l}\text { Product part no. } \\
\text { (Fig.3.) }\end{array}$ & $H_{I}(S)$ & $D(S)$ & Rect $(S)$ & Elong $(S)$ & $A_{I}(S)$ \\
\hline $\mathbf{1}$ & 0.3145 & $\mathbf{0 . 3 8 7 3}$ & 0.8197 & 11.5716 & 0.0072 \\
\hline $\mathbf{2}$ & $\mathbf{0 . 4 0 1 3}$ & $\mathbf{0 . 4 5 6 0}$ & 0.8209 & $\mathbf{2 2 . 0 2 3 9}$ & 0.0067 \\
\hline $\mathbf{3}$ & 0.2741 & $\mathbf{0 . 3 1 7 3}$ & 0.8522 & 8.5709 & 0.0070 \\
\hline $\mathbf{4}$ & $\mathbf{0 . 3 9 6 6}$ & 0.5262 & 0.8349 & $\mathbf{2 1 . 4 3 3 3}$ & 0.0067 \\
\hline $\mathbf{5}$ & $\mathbf{0 . 3 8 7 9}$ & $\mathbf{0 . 4 3 4 2}$ & 0.8053 & $\mathbf{2 0 . 4 1 0 1}$ & 0.0067 \\
\hline $\mathbf{6}$ & $\mathbf{0 . 4 0 3 1}$ & $\mathbf{0 . 4 6 5 2}$ & 0.8278 & $\mathbf{2 1 . 9 8 7 7}$ & 0.0068 \\
\hline $\mathbf{7}$ & $\mathbf{0 . 4 0 1 8}$ & 0.5231 & 0.8204 & $\mathbf{2 2 . 0 7 4 0}$ & 0.0067 \\
\hline $\mathbf{8}$ & $\mathbf{0 . 3 9 0 2}$ & 0.4961 & 0.8034 & $\mathbf{2 0 . 6 4 9 1}$ & 0.0067 \\
\hline
\end{tabular}

Table 2. Computed values of the corresponding measures assigned to the shapes in Fig.3. (A) - (H) by columns

\section{CONCLUSION}

In this paper, we describe certain shape descriptors applied to the tasks of comparing, identifying and classifying the different engineering elements, such as columns of the Classical orders of architecture, as well as the machine elements used as the parts of the production process. Since the shape representation of these two essentially different types of elements have similar characteristic, the same methodology is applied in order to analyze and numerically describe the type of the particular element.

The concept is based on an interdisciplinary approach which uses the shape analysis techniques combined with the certain elements of machine learning and computer vision in order to describe or classify the element type by its shape representation. According to the best knowledge of the authors, so far there are no significant experiences in the ranges that the approach presented in this paper provides in similar tasks.

For the classification of the columns of five orders of Classical architecture, simple shape descriptors, such as the first $\mathrm{Hu}$ moment invariant $H_{l}(S)$, and the measure of the disconnectedness of the components of a shape $D(S)$, are used along with the standard architectural measures of the certain column characteristics based on the proportions of the Classical order elements. The shape descriptors rely on the discrete moments associated with the observed columns. Two global column measures, representing the corresponding extension of the idealized measures of the column proportions are designed. Applying them the main elements of the five Classical orders of architecture are classified. 
In addition to the $H_{l}(S)$, and the $D(S)$, for the numerical characterization of the FMS (Flexible manufacturing systems), the three additional shape descriptors: $\operatorname{Rect}(S)$; $\operatorname{Elong}(S)$; and the first affine moment invariant $A_{l}(S)$ are employed. It is concluded that the achieved numerical results coincide with our perception how such descriptors should act, as well as with the general human perception of the visual characteristics of the elements.

Considering that the initial results are very encouraging, further analysis and development of new shape descriptors of different types of engineering elements are of particular interest in further developing the proposed concept and improving its performance.

\section{REFERENCES}

[1] $\mathrm{Hu}, \mathrm{M}$. (1962). Visual pattern recognition by moment invariants, IRE Transactions on Information Theory, Vol.8, No.2, (February 1962) 179-187, ISSN: $2168-2712$.

[2] Žunić, J., Rosin, L. P., Ilić, V. (2018). Disconnectedness: A new moment invariant for multi-component shapes, Pattern Recognition, Vol.78, (June 2018) 91-102.

[3] Summerson, J. (1966). The Classical Language of Architecture, MIT Press, 9780262190312, Cambridge.

[4] Chitham, R. (2005). The Classical Orders of Architecture, Elsevier, 2nd edition, 9781483278230, Oxford.

[5] Becker, J. - Khan Academy (2019). Tools for understanding art, Available from: https:/www.khanacademy.org/humanities/arthistory-basics/tools-understanding-art/ Accessed: 2019-03-15

[6] Todić, V., Lukić, D., Milošević, M., Borojević, S., Vukman, J. (2011). Application of Simulation Techniques in the Development and Implementation of Flexible Manufacturing Systems. In: XV International Scientific Conference on Industrial Systems. 14.-16. September 2011. pp. 23-28., Novi Sad, Serbia.

[7] Lukić D., Milošević M., Antić A., Borojević S., Đurđev, M. (2018). Manufacturing Process Planning for Flexible Manufacturing Systems. In: 4th International Scientific Conference on Mechanical Engineering Technologies and Applications - COMETa. 27.-30. November 2018, University of East Sarajevo, Faculty of Mechanical Engineering East Sarajevo, ISBN 978-99976-7194-3. 68-76, Jahorina, BiH, 2018.

[8] Mitrofanov, S.P. (1996). The Scientific Principles of Group Technology, National Landing Library Translation, Yorks, UK, Boston Spa.

[9] Burbidge, J.L. (1978). The introduction of group technology. Heineman, London.

[10]Žunić, J., Hirota, K., Rosin, L. (2010). A Hu moment invariant as a shape circularity measure, Pattern Recognition, Vol.43, No.1, (January 2010) 47-57.
[11] Otsu, N. (1979). A threshold selection method from gray-level histograms. IEEE Transactions on Systems, Man, and Cybernetics, Vol. 9, 62-66.

[12]Klette, R., Rosenfeld, A. (2004). Digital Geometry: Geometric methods for digital picture analysis. Morgan Kauufmann, San Francisco

[13]Flusser, J., Tomas, S. (1993). Pattern recognition by affine moment invariants. Pattern Recognition, Vol.26, No.1, (January 1993) 167-174.

\section{ACKNOWLEDGMENTS}

This work was supported by the Ministry of Education, Science and Technological Development of the Republic of Serbia, within the Projects No. ON174009 and No. ON174019.

Authors: PhD student Isidora Đurić, PhD student Vladimir Ilić, Professor Nebojša Ralević PhD, University of Novi Sad, Faculty of Technical Sciences, Trg Dositeja Obradovica 6, 21000 Novi Sad, Serbia,

E-mail: isidoradjuric@uns.ac.rs vlada.mzsvi@uns.ac.rs nralevic@uns.ac.rs 